\title{
Social work's fingerprint on the evolution of attachment theory: Some essential knowledge for care practice
}

\author{
Shirley-Ann Chinnery University of Auckland, New Zealand
}

\begin{abstract}
INTRODUCTION: Social work practice knowledge was seminal to the evolution of attachment theory. This disciplinary connection is little known to many social work practitioners. This article seeks to remind care practice social workers specifically of this association, as the social work skills upon which early attachment knowledge was premised remain important to contemporary care practice.
\end{abstract}

FOCUS: Through a three-part discussion, this article aims to deepen care practice social workers' understanding of attachment theory and its practical relevance for care practice assessment. The first section outlines the watershed moments of the theory's development. The second highlights social work's connection to this development. The third and final section reviews the construct of the internal working model and its value for distinguishing emotional differences in an adult's relational biography.

FINDINGS AND IMPLICATIONS: A key care practice goal is to facilitate the healthy growth and development of children and young people who have been placed in foster care due to maltreatment. A growing number of attachment researchers have found that the internal working model of a child's new caregivers, with respect to attachment, is an important element in the revision of the child's internal working model of relationships (Pace \& Zavattini, 2011). Thus, care practice social workers need to pay close attention to relational facets in prospective caregivers' assessments as some literature suggests that practitioners struggle to understand the role attachment orientation plays in the care relationship (Bick \& Dozier, 2008).

CONCLUSIONS: This article highlights and elaborates upon the utility of attachment theory for present-day care practice and argues that a deep understanding of this theory is likely to be instrumental to achieving better relational outcomes in foster care. This knowledge is foundational to conceptualising the different relational expectancies that prospective foster parents might bring to a new relationship.

KEYWORDS: attachment theory; foster care assessment; secure-base; adult attachment; care quality

\section{Introduction}

A key task of care giving involves the ability to detect and respond to a child or young person's need in a manner that is likely to enhance their security and emotional wellbeing. Accordingly, prospective foster parents need to possess the emotional competencies important to facilitating the formation of attachment security in a new parent-child relationship. A child's healthy growth and development is promoted by such emotionally responsive parenting. Moreover, an international covenant directs
AOTEAROA

NEW ZEALAND SOCIAL WORK 28(3), 79-90.

CORRESPONDENCE TO: Shirley-Ann Chinnery s.chinnery@auckland.ac.nz 
that, "[i]n all matters relating to the placement of a child outside the care of the child's own parents, the best interests of the child, particularly [their] need for affection and right to security and continuing care, should be the paramount consideration" (United Nations, 1986). This sentiment is similarly reflected in Aotearoa New Zealand's own domestic family law, specifically the New Zealand Children Young Persons and Their Families Act 1989, s. 13(h), which asserts:

that where a child or young person cannot [be with] his or her family, whanau, hapu, iwi, and family group, the preeminent principle to be adopted is that the child or young person should be given an opportunity to develop a significant psychological attachment to the person in whose care [they are] placed.

Care practice social workers (CPSW) assessment must be on the relational expectancies that prospective foster parents bring to the new parent-child relationship. Attachment theory offers a useful conceptual map for understanding this and how relational experiences within, and beyond, childhood can influence the way a prospective foster parent may perceive a child placed in their care. Through a threepart discussion, this article aims to deepen a CPSW's understanding of attachment theory and its practical relevance for care practice assessment. The first section outlines the watershed moments of the theory's development. The second highlights social work's connection to this development. The third and final section reviews the construct of the internal working model (IWM) and its value for distinguishing emotional differences in an adult's relational biography. Highlighted in this section is the importance of considering relationships in their cultural context.

\section{Attachment theory: The watershed moments}

John Bowlby (1907-1990) was the theory's creator and his early theoretical ideas were originally advanced in a series of papers (Bowlby, 1940, 1944, 1951, 1958). The thesis that underpinned this work was the view that the quality of a child's care profoundly influenced their immediate and successive social and emotional development. Bowlby's early works were later consolidated into the now internationally acclaimed attachment trilogy: Attachment (1969); Separation (1973); and Loss (1980). The theory itself represented a skilled interweaving of four discrete, then merging, knowledge systems which comprised: (1) ethology; (2) control systems theory; (3) cognitive psychology; and (4) psycho-analytic object relations theory. These knowledge systems are discussed later. The theory has been developed, refined and subjected to robust empirical testing over the ensuing 70 years. In brief, this progress can be broadly traced across four main developmental epochs, noted below.

\section{Early theorising: Attachment is a biological necessity!}

The initial period of theory development involved the generation of constructs important to conceptualising attachment as a motivational system, independent of basic drive fulfilment. Bowlby believed that this relational system was underpinned by psycho-biological properties which encompassed a prefigured affective goal important to maintaining emotional connection between primary kin and/ or their substitutes. He believed this bond operated to ensure a child's safety, comfort and security (Bowlby, 1969, 1973, 1980). Distinct from his own psychoanalytic training, which was premised on theoretical assumptions (Klein, 1948), Bowlby sought scientific grounding. Thus he created the field's first attachment study referred to in the literature as the Forty-four Juvenile Thieves study (Bowlby, 1944).

This study involved a case series methodology aimed at investigating the effects of maternal separation in two groups of children aged between 5 and 16 years. The cases were drawn from referrals to 
London Child Guidance between 1936 and 1939. Forty-four of these children and young people had theft histories, while those allocated to the matched clinic control group $(n=44)$ did not. Children were allocated to one of six predefined groups, according to personality descriptors. One group $(n=14)$, were of particular interest to Bowlby. He described these children as being of affectionless character, i.e., they appeared to lack "normal affection" (Bowlby, 1944, p.24). Reviewing case histories Bowlby found that $86 \%$ had been exposed to extensive disruption through separation from their primary attachment figure at very young ages. Only $10 \%$ of the control group shared this experience.

Additionally, a number of children in the thieves group, unlike those in the control group, presented with other behavioural challenges comprising: lying, stealing, depression, episodic aggression toward others, poor academic performance, hyperactivity and attentional problems. The findings provided Bowlby with seminal verification of the important role care continuity played in child development and the concomitant negative impact exerted by adverse and discontinuous care. The social work perspective was pivotal to grounding Bowlby's developing conceptualisation of the nature of the care relationship in practice. The specifics of this relationship are discussed in section two. Suffice it to say here that dedicated study on the long- and short-term separations of children from their primary caregivers was instrumental to strengthening and advancing Bowlby's developing attachment claims (Bowlby \& Robertson, 1953; Robertson, 1953). Without this work, the next watershed moment in attachment theory would not have been possible.

\section{Quality of the parent-child relationship shapes child's attachment pattern}

Mary Ainsworth (1967) produced

the field's ground-breaking study on

attachment patterns in early childhood.
The methodology she applied was a simple, direct, naturalistic observation of young children and their mothers. The conceptual and empirical work prefiguring this study was directly attributable to James Robertson's (1911-1988) influence (Bretherton, 1992, 2006, 2013). Robertson was a psychiatric social worker employed by Bowlby in the Tavistock clinic in 1948. Bowlby's decision to employ Robertson was predicated on two key factors: his disciplinary training as a social worker and his thorough training in child observation (Bretherton, 1992; Van Dijken, van der Veer, Van Ijzendoorn, \& Kuipers, 1998).

Robertson's contribution to attachment theory is elaborated upon in the paper's second section. Specific to Robertson's practice is the person-in-environment construct, a major disciplinary tenet of social work. It is worth noting here that Ainsworth's use of naturalistic observation was inspired by Robertson's cogent use of situated knowledge reflected in Ainsworth's comment:
All of his data on mother-child interactions and relationships - [were compelling] in indexing the effects of prolonged early separations - [and] came from visiting the children in their homes and separation environments and observing [and] listening .... The power of his observations in reflecting [and] communicating it effectively ... impressed me very much, so I took direct observation as my own model. (Ainsworth \& Marvin, 1995, p. 5)

Ainsworth's (1967) subsequent study supplied Bowlby with crucial empirical support for his thesis about the role that care quality played in a child's socio-emotional development. The first of three patterns of attachment of early childhood were pioneered through this work and codified as follows: (1) secure (b); (2) insecureavoidant (a); and (3) insecure ambivalent or resistant (c); (see Ainsworth, Blehar, Waters, \& Wall, 1978). 
A fourth classification later joined the foundational three (B, A and C), after a conceptual battle waged in the literature by three, now equally well known, thirdgeneration attachment theorists (Crittenden, 1988, 1992; Main \& Solomon, 1990). The fourth category was subsequently classified as disorganised (D) (Main \& Solomon, 1990). The next defining moment in attachment theory was the identification of adult attachment patterns which follows.

\section{Experience in close relationships influences adult attachment}

Empirical support for Bowlby's constructs of the internal working model with respect to adult attachment was not evident until the mid-1980s. The researchers responsible for this breakthrough were George, Kaplan, and Main (1985), whose finding confirmed another of Bowlby's early conceptual propositions: that the attachment system continued to be active throughout life and remained an important influence in shaping an adult's perception and experience of close relationships (Bowlby, 1988). George et al. (1985) developed the Adult Attachment Interview (AAI), a semi-structured interview protocol that invites participants to respond to a series of open-ended, attachmentbased questions. Respondents are asked to recall and reflect upon their relationship with principal care giving figures in their childhood. They are subsequently asked to relate experience of this care to the way they were treated when scared, ill, hurt, upset or separated from the specified attachment figures. Questions also relate to the impact their early care experiences may have on current relationships with these key figures and in relation to their own children, if applicable.

The interviewees' responses are subsequently analysed using a methodology based on narrative integrity (Main, Hesse, \& Goldwyn, 2008). Close attention is paid to the way an adult narrates both their early relational history and their current relationship with key attachment figures. Individual differences in attachment are discriminated by the level of coherence and organisation identified in responses. Three distinct classification patterns of adult attachment emerged from this ground-breaking research: (1) secureautonomous (F); (2) dismissing (D); and (3) pre-occupied (E). Two further categories were added to these: (4) unresolveddisorganised (U-d) with respect to trauma and loss; and (5) cannot classify. These strategies are discussed more fully later. Over the last 20+ years, work in the attachment field has concentrated on translating vital principles from theory and science into clinically useful practices. Some examples relevant to the field of foster care now follow.

\section{Bowlby's dream realised: Fostering healthy relationships through attachment interventions}

As stated, over the last few decades and especially within the last decade, the attachment field has focussed on developing clinical interventions aimed at facilitating positive change in distressed relationships. Of interest to the care practice context are interventions such as the: Attachment and bio-behavioural catch-up (ABC) (Bick \& Dozier, 2013); circle of security (COS) (Powell, Cooper, Hoffman, \& Marvin, 2014); creating loving attachments: parenting with PACE (Golding \& Hughes, 2012); nurturing attachments: supporting children who are fostered or adopted (Golding, 2008); and the fostering attachments programme (Golding, 2006). These applications are primarily concerned with identifying and enhancing a foster parent's capacity for sensitive and emotionally responsive care giving.

Some attachment-informed studies in the foster care field have found that foster parents present with higher rates of attachment insecurity than members of the general population (Ballen, Bernier, Moss, Tarabulsy, \& St-Laurent, 2010; Steele et al., 2008). 
The literature shows that, when maltreated, children are placed with attachmentinsecure foster parents and, independent of their early experiences of care adversity, they are more likely to become relationally disorganised (Ballen et al., 2010; Barone \& Lionetti, 2012; Bates \& Dozier, 2002; Steele, Hodges, Kanuik, \& Steele, 2010). Significant emotional, behavioural, relational, social and academic difficulties are associated with attachment disorganisation in childhood (Fearon, Bakermans-Kranenburg, van Ijzendoorn, Lapsley, \& Roisman, 2010; Juffer, Bakermans-Kranenburg, \& van Ijzendoorn, 2005). Moreover, it is also predictive of later mental health problems in adolescence and adulthood (Van Ijzendoorn, Schuengel, \& BakermansKranenburg, 1999). These research findings point to the vital importance of ensuring that the relational histories of prospective foster parents are robustly explored during pre-placement are practice assessments.

Against this conceptual background, social work's influence on attachment theory is now explored below.

\section{Social work's influence on attachment theory}

Social work can claim to have influenced the development of attachment theory in three key ways: (1) in its focus on the actual or lived vs. fantasised experience of the parent-child relationship (Bowlby, 1940);

(2) in relation to the impact of loss on a parent's childhood experience of being parented (Bowlby, 1940; Bretherton, 1992; Sable, 2011); and (3) through the use of direct, naturalistic observation as a lens for accessing information about the relational quality endemic to a parentchild relationship (Bowlby \& Robertson, 1953; Bretherton, 2013; Robertson \& Robertson, 1989; Winnicott, 1952). These three influences are considered because of their seminal impact on the theory and their enduring importance to contemporary practice.

\section{The relevance of actual lived experience}

Social work's influence on the genesis of attachment theory was first inspired by two psychoanalytically oriented social work colleagues with whom Bowlby worked and studied during his time at the London Child Guidance Clinic (Van Dijken et al., 1998). Bowlby was intrigued by the person-in-environment focus that his social work colleagues, Molly Lowden and Nance Fairburn, applied to their work. Bowlby had long held the view that a person's interaction with their environment was central to a child's socio-emotional development. However, this stance was contrary to his own theoretical training which emphasised the primacy of the internal world (Bretherton, 1992). The person-in-environment perspective, pivotal to social work training, (Cornell, 2006), represented an innovative thinking frame not offered or sanctioned by his discipline. Moreover, this stance provided a goodness of fit with Bowlby's developing views about the role environment played in a child's emotional development. Specifically, his social work colleagues encouraged him to consider his patients' accounts based on their actual or lived experience in their daily lives (Bretherton, 1992). Bowlby acknowledges Lowden and Fairburn's influence on his foundational conceptualising on attachment in one of his early papers (Bowlby, 1940) and again during a later interview where he asserted "I learned a hell of a lot from them [Molly Lowden and Nance Fairburn] I learned far more from those two social workers than I learned from my psychiatric colleagues" (Smuts, 1977, pp. 9-11, cited in Van Dijken et al. 1999).

Encouraged by the perspective of his social work colleagues, Bowlby started to actively interrogate his own clinical work for the relational elements that might better explain his young patients' emotional troubles. This led Bowlby to implementing the field's first research study: the Forty-four Juvenile Thieves study discussed earlier (Bowlby, 1944). 


\section{The impact of childhood loss}

Fairburn and Lowden also supported Bowlby to actively consider to what extent his young patients' predicament might have been influenced by the nature of their relationship with their own parents (Sable, 2011). Moreover, these colleagues also suggested that he reflect on the parents' childhood histories of parenting as their tacit practice knowledge signalled that losses sustained in early childhood may contribute to later emotional difficulties encountered in parenting. Subsequent research on adult attachment has established that unresolved emotional experience in childhood (e.g., loss) is regularly associated with attachment insecurity in adults (George \& West, 2011). This finding confirms the social workers' early, practice-based conceptualisations. Social work's next influential contribution to attachment theory was the use of simple, direct, naturalistic observation.

\section{Noticing, describing and analysing behaviour: James Robertson's contribution}

Attachment theory, as discussed thus far, is comprised of a number of discernible watershed moments. Observation as a tool to better understand relational quality might be among the most compelling contributions made by social work practice toward better understanding the importance of the care giving relationship and its impact on a child's socio-emotional development. Bowlby's (1969) collaboration with James Robertson is credited for this development. As mentioned earlier, James Robertson was a psychiatric social worker appointed to the Tavistock by Bowlby for his observational expertise and person-in-environment perspective. Robertson and Bowlby put these conceptual and practice skills to immediate use in detailing the distress experienced by young children when separated from care giving figures (typically, at that time, mothers). Robertson proposed a three-stage model of childhood grief based on this work, comprised of: (1) protest; (2) despair; and
(3) denial/detachment (Robertson \& Bowlby, 1952). Robertson's view was derived from the many observations he had made of young children separated from their parents and placed in residential nurseries as a result of the Second World War (Burlington \& Freud, 1942).

Robertson also possessed cinematic skills which proved fruitful to launching attachment theory as a world-wide phenomenon; he was able to technically depict the behavioural changes young children experienced when separated from primary caregivers. His professional social work training enabled him to articulate the meaning of these changes to the interdisciplinary audiences viewing his films. With Bowlby's endorsement, Robertson made a range of films that portrayed a child's reaction to separation from its primary attachment figure. The first of these now famous films is A Two year old goes to hospital (Bowlby \& Robertson, 1953), a synopsis of which can be found in Winnicott's (1952) editorial for the Royal Society of Medicine.

This film, and others, met with a hostile reception from the interdisciplinary group of hospital staff who attended the initial screenings. The emotional impact of the films on staff was identified as a contributor to the negative reaction at the time (Robertson \& Robertson, 1989; Winnicott, 1952). However, the key charge against the films was championed by the medical fraternity who were seriously concerned about the medical risks, for example, crossinfection, that might accompany greater rates of parent-child contact following hospital admission. Concerns were also expressed about the emergent distress children appeared to experience when parents were permitted to visit. Criticisms of methodological rigour were also levelled at the case method upon which the films were premised. In short, these films challenged the biomedical perspective. Excluding parents from children during hospital stays was then routine practice. According to van der Horst, 
Frank, and van der Veer (2009), parents were conceptualised "as ignorant and noisy intruders who only criticized the staff and disturbed the quiet and disciplined course of events in the ward" (p.124). Despite the initial resistance these films, became instrumental in changing the face of hospital policy internationally by, championing the right of parents to accompany their young throughout their hospital stay (Alsop-Shields \& Mohay, 2001).

More critically, Robertson's influence has had a lasting impact on the development of attachment theory. The continued use of visual technologies in the attachment field is historically linked to his early and compelling cinematic work. Current-day attachment interventions use video or digital feedback as a mechanism to promote change in distressed relationships largely by enhancing caregiver sensitivity and emotional attunement (COS: Powell et al., 2014; ABC: Bick \& Dozier, 2013).

\section{The importance of a relational focus in care practice assessments}

Three elements for practice were amplified in this brief review of social work's seminal influence on attachment theory. These practices remain relevant to social work in general and are of particular importance to the field of contemporary care practice. The resultant information suggests that practitioners need to: (1) access and listen attentively to an adult's lived experience of close relationships. This history offers important clues as to the strengths, vulnerabilities and struggles that prospective foster parents might encounter in new relational affiliations such as those required in a foster parent-child relationship; (2) collectively reflect on the relational biographies gathered, with the prospective foster parents, to ascertain what role close relationships might have played in resolution of any evident trauma and loss, across the life course; and (3) learn to apply a systematic method of naturalistic observation to understand more about the emotional quality present in a parent-child relationship.

Attachment research suggests that ways of being in close relationships are intergenerational and, when considered in the context of the parent-child relationship: care giving adults are highly likely to parent the way they were parented (Hautamäki, Hautamäki, Neuvonen, \& MaliniemiPiispanen, 2010; Van Ijzendoorn, 1992). The transmission pathway for care quality is expressed through parenting behaviour while different internal working models of relationships are known to develop from different care experiences (see Ainsworth et al., 1978).

Positive internal working models (security) of self and others typically result when one's care giving experience has been continuously reliable and responsive. Conversely, negative internal working models (insecurity) arise in correspondence with care giving characterised by rejection, neglect, inconsistency, fear and/or emotional unresponsiveness. Attachment insecurity, as indicated earlier, is associated with poor developmental outcomes in children. Thus it is essential that CPSWs are able to recognise the characteristics associated with an adult's IWM as these relational attributes are highly likely to influence the quality of care a fostered child receives. Accordingly, the final part of this article explores attachment theory's construct of the IWM.

\section{The internal working model and patterns of adult attachment}

The internal working model, according to Bowlby (1973) represented a relational blueprint formed from the myriad of interactions enacted between the self and significant care giving figures in childhood. Drawing on early cognitive theory, he claimed that it was the actual experience of care giving (i.e., parenting behaviour) that became cognitively encoded in memory as a schema that would subsequently guide the way future relationships would be perceived. 
Memory encoding studies have since found that perception does, in fact, appear to be shaped by experiences; a finding consistent with current neurobiological understandings about the brain as a habit-dependent entity (Schore \& Schore, 2011): once an experience becomes stamped in the brain, the greater the likelihood that it will be encoded in the mind for later recall. Knudsen (2004) asserts that the human brain is shaped by experience; the care giving environment is a key influence on the development of a young child's brain and the more a neural circuitry is activated in the brain through experience (e.g., care giving) the more likely it is to be instantiated. Knudsen (2004) cautions that, although the brain is structurally capable of change based on new inputs such as a new sensitively responsive care giving experience represents, there are constraints on the brain's malleability. Recent attachment studies show that a fostered child's IWM can be positively revised, particularly where very young children have been placed with emotionally responsive foster parents (Bates \& Dozier, 2002; Bick \& Dozier, 2008). While similar relational shifts have been identified in older children, the rate of relational change is much slower (Steele et al., 2010).

In relation to this neurobiological knowledge, the AAI (George et al., 1985) protocol was developed to investigate whether an adult's recall of significant relationships in childhood would clarify how those early relationships might influence an adult's perceptions. The researchers believed that the AAI questions worked to surprise the unconscious, thus revealing the way an adult comes to mentally represent their relational experience. As previously outlined, three distinct patterns of adult attachment emerged from this analysis:

(1) secure-autonomous (F); (2) dismissing (D);

(3) pre-occupied (E) (and subsequently

(4) unresolved-disorganised (U-d) with respect to trauma and loss). In brief, relationally secure adults possess the ability, on inquiry, to readily access autobiographical memories of childhood. They subsequently display ease in communicating openly and directly about their significant past and current relational experiences, even emotionally distressing events. The key relational belief and expectation of secure adults is that significant others will be available and responsive to their needs. These adults typically value relationships - not only do they seek support and care when needed but they also possess reciprocating capacities.

An earned-secure relational orientation was identified in later attachment research (Roisman, Padrón, Sroufe, \& Egeland, 2002). This status was noted in adults who, while narrating difficult and abusive early care experiences, were able to relay this experience in coherent and reflective ways suggestive of a positive revision in relational orientation. Recent research in the attachment field of couple relationships suggests that change in one's relational approach in adulthood might result from the buffering effect afforded from being in relationships with emotionally responsive partners (Overall, Simpson, \& Struthers, 2013).

In contrast, adults who have not experienced close, relationally responsive partnerships, in either childhood or adulthood, are more likely to develop insecure relational strategies. Adults with dismissing (D) states of mind are discomfited by the proximity required in close relationships and thus use a range of deactivating strategies to suppress or inhibit emotional closeness. Adults with this relational orientation value self-reliance over emotional connection with others. The narrative markers common to this relational position include: not being able to remember; normalising distressing experiences in relationships; and reporting invulnerability to the emotional needs of others.

The preoccupied attachment strategy, on the other hand, is beset by ambivalence and anxiety. Adults who inhabit this stance are often described as entangled with relational experience from the past. They find it relatively easy to recall their experience of care in early relationships but frequently 
lack the capacity to describe these in a coherent or succinct manner. Moreover, past experiences notably intrude on their description of current relationships. The relational state of most concern, specifically from a care practice perspective, involves adult experiences of unresolved trauma and loss. Adults operating from this stance have been described as frightening and disorienting to children because their shift in mind states can be rapid and unpredictable (George \& West, 2011). These mind states are narratively displayed through momentary lapses in reasoning. Behaviourally, this presentation is associated with marked emotional dysregulation.

A sound understanding of the foregoing conceptual knowledge is important to care practice assessments of prospective foster parents as these individuals, once selected, will be the fostered child's new attachment figures. As identified earlier, change to an IWM is possible when new and discrepant experience in close relationships challenge the extant IWM, thus prompting the prospect of relational revision. Consequently, CPSWs need to reliably select prospective foster parents possessing the most optimal relational strategy for facilitating this outcome in the fostered child.

The prospect for attachment revision has been realised in this population, as earlier attested, by a growing body of research involving maltreated children who have been both fostered and adopted from State care (Dozier, Stovall, Albus, \& Bates, 2001; Pace \& Zavattini, 2011). Notable from these studies are the positive shifts found in a child's relational expectancies when placed with caregivers assessed as attachment secure (Pace \& Zavattini, 2011; Steele et al., 2010). Such adults are more likely to override the child's invitation for them to respond in kind, by not employing distancing strategies in the face of distress or responding angrily when the child makes persistent and demanding bids for proximity (Bick \& Dozier, 2008). Instead, emotionally secure adults characteristically possess the capacity to flexibly appraise their experience and to modify their behaviour in accordance with feedback. These emotional skills are important to the provision of secure-base care which, in the fostering context, requires caregivers to recognise and understand a child's typically dysregulated care-seeking behaviour. Foster parents' sensitive responses to a vulnerable child's attachment needs, despite the consequent distortion, are fundamental to reawakening a child's trust in their attachment figures and in revising their own perceptions of themselves as loveable and worthy of care and protection. Cultural identity is equally pivotal to a child's sense of security. The negative impact of cultural dislocation, specifically of mokopuna Māori in foster care, is domestically well known. This outcome signals the need to ensure that all assessments of relational closeness be culturally grounded. This matter is considered further below.

\section{Culture, attachment, law and care practice social work}

Cross-cultural attachment research strongly suggests that connectedness amongst close others is species-specific, but research on how culture influences attachment outcomes in different societies is inchoate (Agishtein \& Brumbaugh, 2013). Currently there is little attachment research from a Māori perspective. This is a critical knowledge gap for CPSW in Aotearoa New Zealand given the profession's bicultural practice obligations under Te Tiriti O Waitangi (ANZASW, 2008) and in light of the disproportionate numbers of Māori children entering the care system (OCC, 2016). Presently, sections 5 and 13 of the Children Young Persons and Their Families Act 1989 direct that a child's connection to their whānau, hapū and iwi be consciously promoted throughout the placement process. From this perspective, cultural identity is positioned as a vital strength in the development of a child's coherent sense of self. 
Care sector practice reality (e.g., placement urgency, kin availability, work volume) often compromises the principles and might result in mokopuna Māori being placed in non-Māori families. The longer such placements continue the more problematical for all involved in the care relationship as it heightens the prospect of emotional bonds forming between the placed child and their respective caregiver(s). Case dependent, the attachment paradigm and legal process, may be applied to endorse the continuance of the new relationship. The iatrogenic impact of this care drift needs to be recognised by CPSWs and remedied in the crisis phase. Building cultural capability within the CPSW workforce will be an essential step toward resolving this dilemma. Where placements external to the kinship system are required, assessing cultural receptivity of prospective foster parents appears warranted. Developing a reliable tool to support CPSWs in this assessment may prove fruitful, particularly in light of the litigious disputes evident in case law between kin and non-kin caregivers.

\section{Conclusion}

In summary, this article has offered discussion aimed at deepening CPSWs' understanding of attachment theory and its practical relevance for care practice assessment. Three important contributions made by social work to the development of attachment theory were emphasised. Social workers in the care practice field need to recognise the theoretical utility of attachment knowledge as an important conceptual tool in the assessments of prospective foster parents as an adult's attachment capacity has a profound impact on care quality. A growing number of attachment studies conducted within the fostering population show that developmental catchup and healthy adjustment are more likely when children are placed with substitute caregivers (when required) who themselves possess the ability to be an effective securebase.
Traumatised children need caregivers with high levels of emotional competence. Some foster parents, based on emotional aptitude, are more likely to weather the relational storms involved in caring for the hurt child in transformational ways. As highlighted above, it is essential that these assessments are culturally grounded. CPSWs need, at the point of assessment, to be able to consistently and reliably recognise the relational contributions that prospective caregivers bring to the care relationship. This article has argued that a deep understanding of attachment theory is likely to be instrumental to achieving this outcome as this knowledge is foundational to conceptualising the different relational expectancies that prospective foster parents might bring to a new relationship.

\section{References}

Agishtein, P., \& Brumbaugh, C. (2013). Cultural variation in adult attachment: The impact of ethnicity, collectivism, and country of origin. Journal of Social, Evolutionary, and Cultural Psychology, 7(4), 384-405. http://dx.doi.org/10.1037/h0099181

Ainsworth, M. D. S. (1967). Infancy in Uganda: Infant care and the growth of love. Baltimore, MD: The Johns Hopkins Press.

Ainsworth, M., Blehar, M. C., Waters, E., \& Wall, S. (1978). Patterns of attachment: A psychological study of the strange situation. Hillsdale, NJ: Erlbaum.

Ainsworth, M. D. S., \& Marvin, R. S. (1995). On the shaping of attachment theory and research: An interview with Mary D. S. Ainsworth (Fall 1994). Monographs of the Society for Research in Child Development, 60(2-3), 3-21. doi: 10.1111/j.1540-5834.1995.tb00200.x

Alsop-Shields, L., \& Mohay, H. (2001). John Bowlby and James Robertson: Theorists, scientists and crusaders for improvements in the care of children in hospital. Journal of Advanced Nursing, 35(1), 50-58. doi: 10.1046/ j.1365-2648.2001.01821.x

Aotearoa New Zealand Association of Social Workers (ANZASW). (2008). Code of ethics and bicultural code of practice. Christchurch, NZ: Author.

Ballen, N., Bernier, A., Moss, E., Tarabulsy, G. M., \& St-Laurent, D. (2010). Insecure attachment states of mind and atypical caregiving behavior among foster mothers. Journal of Applied Developmental Psychology, 31(2), 118-125. doi: 10.1016/j.appdev.2009.10.001

Barone, L., \& Lionetti, F. (2012). Attachment and emotional understanding: A study on late-adopted pre-schoolers and their parents. Child: Care, Health and Development, 38(5), 690-696. doi: 10.1111/j.1365-2214.2011.01296.x

Bates, B., \& Dozier, M. (2002). The importance of maternal state of mind regarding attachment and infant age at placement to foster mothers' representations of their foster infants. Infant Mental Health Journal, 23(4), 417-431. doi: 10.1002/imhj.10022 
Bick, J., \& Dozier, M. (2008). Helping foster parents change: The role of parental state of mind. In $\mathrm{H}$. Steele, \& M. Steele (Eds.), Clinical applications of the adult attachment interview (pp. 452-470). New York, NY: The Guildford Press.

Bick, J., \& Dozier, M. (2013). The effectiveness of an attachment-based intervention in promoting foster mothers' sensitivity toward foster infants. Infant Mental Health Journal, 34(2), 95-103. doi: 10.1002/imhj.21373

Bowlby, J. (1940). The influence of early environment in the development of neurosis and neurotic character. The International Journal of Psychoanalysis, 21, 154-178.

Bowlby, J. (1944). Forty-four juvenile thieves: Their characters and home life. International Journal of Psycho-Analysis, 25, 19-52.

Bowlby, J. (1951). Maternal care and mental health, 3, 355-534. Geneva, Switzerland: Bulletin of the World Health Organisation.

Bowlby, J. (1958). The nature of the child's tie to his mother. International Journal of Psychoanalysis, 39, 350-373.

Bowlby, J. (1969). Attachment. London, UK: Penguin Books.

Bowlby, J. (1973). Attachment and loss: Vol 2:Separation. New York, NY: Basic Books.

Bowlby, J. (1980). Attachment and loss: Vol.3:Loss, sadness and depression. New York, NY: Basic Books.

Bowlby, J. (1988). A secure base: Parent-child attachment and healthy human development. New York, NY: Basic Books.

Bowlby, J., \& Robertson, J. (1953). A two-year old goes to hospital. Proceedings of the Royal Society of Medicine, 46(6), 425-427.

Bretherton, I. (1992). The origins of attachment theory: John Bowlby and Mary Ainsworth. Developmental Psychology, 28(5), 759-775. doi: http://dx.doi.org/10.1037/00121649.28.5.759

Bretherton, I. (2006). The roots and growing points of attachment theory. In C. M. Parkes, J. Stevenson-Hinde \& P. Marris (Eds.), Attachment across the life cycle (pp. 9-32). Florence, US: Routledge.

Bretherton, I. (2013). Revisiting Mary Ainsworth's conceptualization and assessments of maternal sensitivityinsensitivity. Attachment \& Human Development, 15(5-6), 460-484. doi: 10.1080/14616734.2013.835128

Burgess Moser, M., Johnson, S. M., Dalgleish, T. L., Lafontaine, M., Wiebe, S. A., \& Tasca, G. A. (2016). Changes in relationship-specific attachment in emotionally focused couple therapy. Journal of Marital and Family Therapy, 42(2), 231-245. doi: 10.1111/jmft.12139

Burlington, D., \& Freud, A. (1942). Young children in wartime: $A$ year's work in a residential war nursery. London, UK: Allen \& Unwin

Cornell, K. L. (2006). Person-in-situation: History, theory, and new directions for social work practice. Praxis, 6(Fall 2006), 50-57.

Crittenden, P. M. (1988). Relationships at risk. In J. Belsky \& T. Nezworski (Eds.), Clinical implications of attachment (pp. 136-174). Hillsdale, NJ: Erlbaum.

Crittenden, P. M. (1992). Quality of attachment in the preschool years. Development and Psychopathology, 4(2), 209-241.doi: 10.1017/S0954579400000110
Dozier, M., Stoval, K. C., Albus, K. E., \& Bates, B. (2001) Attachment for infants in foster care: The role of caregiver state of mind. Child Development, 72(5), 14671477. doi: 10.1111/1467-8624.00360

Fearon, R., Bakermans-Kranenburg, M. J., van ljzendoorn, M. H., Lapsley, A. M., \& Roisman, G. I. (2010). The significance of insecure attachment and disorganization in the development of children's externalizing behavior: A meta-analytic study. Child Development, 81(2), 435456. doi: 10.1111/j.1467-8624.2009.01405.x

George, C., Kaplan, N., \& Main, M. (1985). Attachment interview for adults. Unpublished manuscript, University of California, Berkeley.

George, C., \& West, M. (2011). The adult attachment projective picture system: Integrating attachment into clinical assessment. Journal of Personality Assessment, 93(5), 407-416. doi: 10.1080/00223891.2011.594133.

Golding, K. (2006). 'Forgotten miseries': Can attachment theory help to guide interventions? In K. Golding, H. Dent, R. Niccism and L. Stott (Eds.), Thinking psychologically about children who are looked after and adopted: Space for reflection (pp. 333-347). Chichester, England: John Wiley \& Sons.

Golding, K. S. (2008). Nurturing attachments: Supporting children who are fostered or adopted. London, UK: Jessica Kingsley Publishers.

Golding, K. S., \& Hughes, D. A. (2012). Creating loving attachments: Parenting with PACE to nurture confidence and security in the troubled child. London, UK: Jessica Kingsley Publishers.

Hautamäki, A., Hautamäki, L., Neuvonen, L., \& MaliniemiPiispanen, S. (2010). Transmission of attachment across three generations. European Journal of Developmental Psychology, 7(5), 618-634.doi: 10.1080/17405620902983519

Juffer, F., Bakermans-Kranenburg, M. J., \& Van ljzendoorn, M. H. (2005). The importance of parenting in the development of disorganized attachment: Evidence from a preventive intervention study in adoptive families. Journal of Child Psychology \& Psychiatry, 46(3), 263274. doi: 10.1111/j.1469-7610.2004.00353.x

Klein, M. (1948). Contributions to psychoanalysis, 1921-1945. Honolulu, HI: Hogarth Press.

Knudsen, E. (2004). Sensitive periods in the development of the brain and behavior. Journal of Cognitive Neuroscience, 16(8), 1412-1425. doi: 10.1162/0898929042304796

Main, M., Hesse, E., \& Goldwyn, R. (2008). Studying differences in language usage in recounting attachment history. In H. Steele \& M. Steele (Eds.), Clinical applications of the adult attachment interview (pp. 31 68). New York, NY: The Guildford Press.

Main, M., \& Solomon, J. (1990). Procedures for identifying infants as disorganized/disoriented during the Ainsworth strange situation. In M. T. Greenberg, D. Cicchetti, \& E. Cummings (Eds.), Attachment in the preschool years (pp. 121-160). Chicago, IL: University of Chicago Press.

New Zealand Children, Young Persons, and Their Families Act, ss. 5 and 13 (h) (1989).

Office of the Children's Commissioner. (2016). State of Care 2016: What we learnt from monitoring Child, Youth and Family. Wellington, NZ: Office of the Children's Commissioner. 
Overall, N. C., Simpson, J. A., \& Struthers, H. (2013). Buffering attachment-related avoidance. Journal of Personality and Social Psychology, 104(5), 854-871. doi: $10.1037 / a 0031798$

Pace, C. S. Z., \& Zavattini, G. (2011). 'Adoption and attachment theory': The attachment models of adoptive mothers and the revision of attachment patterns of their late-adopted children. Child: Care, Health \& Development, 37(1), 82-88. doi: 10.1111/j.13652214.2010.01135.x

Powell, B., \& Cooper, G., Hoffman, K. \& Marvin, B. (2014). The circle of security intervention: Enhancing attachment in early parent-child relationships. New York, NY: Guilford Press.

Robertson, J., \& Bowlby, J. (1952). Responses of young children to separation from their mothers. Courier of the International Children's Centre: Paris, II, 131-140.

Robertson, J. (Director). (1953). A two-year-old goes to hospital: A scientific film record [Motion picture]. Concord Film Council, Nacton.

Robertson, J., \& Robertson, J. (Directors). (1958). Going to hospital with mother [Motion picture]. Robertson Films.

Robertson, J., \& Robertson J. (1989). Separation and the very young. London, UK: Free Association Books.

Roisman, G. I., Padrón, E., Sroufe, L. A., \& Egeland, B. (2002). Earned-secure attachment status in retrospect and prospect. Child Development, 73(4), 1204-1219. doi: 10.1111/1467-8624.00467

Sable, P. (2011). The origins of an attachment approach to social work practice with adults. In S. Bennett, \& J. Nelson (Eds.), Adult attachment in clinical social work practice, research, and policy (pp. 17-29). New York, NY: Springer. doi: 10.1007/978-1-4419-6241-6

Schore, J. R., \& Schore, A. N. (2011). Clinical social work and regulation theory: Implications of neurobiological models of attachment. In S. Bennett, \& J. K. Nelson (Eds.), Adult attachment in clinical social work (pp. 5775). New York, NY: Springer.

Steele, M., Hodges, J., Kaniuk, J., \& Steele, H. (2010). Mental representation and change: Developing attachment relationships in an adoption context. Psychoanalytic Inquiry, 30(1), 25-40. doi: 10.1080/07351690903200135

Steele, M., Hodges, J., Kaniuk, J, Steele, H., Hillman, S., \& Asquith, K. (2008). Forecasting outcomes in previously maltreated children: The use of the AAl in a longitudinal adoption study. In H. Steele \& M. Steele (Eds.). Clinical applications of the Adult Attachment Interview (pp. 427451). New York, NY: Guilford Press.

United Nations. (1986). Declaration on social and legal principles relating to the protection and welfare of children, with special reference to foster placement and adoption nationally and internationally (A/Res/41/85). Retrieved from http://www.un.org/documents/ga/res/41/ a41r085.htm

Van der Horst, Frank C. P, \& Van der Veer, R. (2009). Changing attitudes towards the care of children in hospital: A new assessment of the influence of the work of Bowlby and Robertson in the UK, 1940-1970. Attachment \& Human Development, 11(2), 119-142. doi: 10.1080/14616730802503655

Van Dijken, S., van der Veer, R., van ljzendoorn, M., \& Kuipers, H. (1998). Bowlby before Bowlby: The sources of an intellectual departure in psychoanalysis and psychology. Journal of the History of the Behavioral Sciences, 34(3), 247-269.

Van ljzendoorn, M. H., Schuengel, C., \& BakermansKranenburg, M. J. (1999). Disorganized attachment in early childhood: Meta-analysis of precursors, concomitants, and sequelae. Development and Psychopathology, 11(02), 225-250. doi: 10.1017/ s0954579499002035

Van ljzendoorn, M. H. (1992). Intergenerational transmission of parenting: A review of studiesin non-clinical populations. Developmental Review 12, 76-99.doi: 10.1016/0273-2297(92)90004-L

Winnicott, D. W. (1952). A two-year-old goes to hospital. Proceedings of the Royal Society of Medicine, 46(425), $11-13$. 